\title{
Burn Septicaemia in Kuwait: Associated Demographic and Clinical Factors
}

\author{
Rameshwar L. Bang ${ }^{a, b}$ Prem N. Sharma ${ }^{c}$ Suhas C. Sanyald Sarla Bange \\ Mohammed K. Ebrahim ${ }^{a}$ \\ ${ }^{a}$ Al-Babtain Centre for Plastic Surgery and Burns, ${ }^{b}$ Department of Surgery, Faculty of Medicine, \\ 'Health Sciences Computer Centre, Kuwait University, dDepartment of Microbiology, Ibn Sina Hospital, and \\ eAl Bahar Eye Centre, Ibn Sina Hospital, Kuwait
}

\section{Key Words}

Burns - Septicaemia - Microbes · Methicillin-resistant

Staphylococcus aureus $\cdot$ Mortality

\begin{abstract}
Objective: To study the demographic and clinical factors associated with burn septicaemia patients in Kuwait. Materials and Methods: All burn in-patients, who developed septicaemia at the Burns Unit, Al-Babtain Centre for Burns and Plastic Surgery, Kuwait, during a 9-year period (June 1992 to May 2001) were included in the study. The data were recorded for age, sex, nationality, cause and percentage of burns, inhalation injury, resuscitation, number of episodes, septicaemia on post-burn day, the microorganisms responsible in each episode, treatment and outcome for statistical analysis. Using SPSS (PC version 11.0) software, a probability level of $p<0.05$ was considered significant. Results: Of the 2,082 patients treated in the Burns Unit, 166 [8\%; 99 (60\%) males and 67 (40\%) females] with a mean age of 26 years (range 1-70) had septicaemia. Significantly higher ( $p<$ $0.001)$ cases were recorded among Kuwaiti children ( $\leq 14$ years) and non-Kuwaitis (25-59 years) than other corresponding age groups. The total body surface area burned ranged from 2 to $95 \%$ (mean $42 \%$ ) and the main cause of burn was flame $(77.1 \%)$. Inhalation injury was
\end{abstract}

\section{KARGER}

Fax +41613061234

E-Mail karger@karger.ch

www.karger.com (c) 2004 S. Karger AG, Basel

1011-7571/04/0133-0136\$21.00/0

Accessible online at:

www. karger.com/mpp diagnosed in 39 (23.5\%) patients. A total of 253 septicaemic episodes occurred in all patients. The majority, $123(74.1 \%)$, had a single episode and the remaining 43 (25.6\%) had multiple (2-10) episodes. One hundred and fifty-five $(61.3 \%)$ episodes were due to gram-positive organisms, mainly methicillin-resistant Staphylococcus aureus, and 32 (12.7\%) were polymicrobial. One hundred and twenty-four $(74.7 \%)$ patients had wound excision and skin grafting procedures and their survival was significantly higher $(\mathrm{OR}=4.3 ; 95 \% \mathrm{Cl}: 1.98-9.31$ ) than nonsurgically treated patients. Thirty-nine $(23.5 \%)$ patients died mainly due to multi-organ failure. Conclusion: The findings indicate that the patients with extensive flame burns were prone to developing septicaemia due mainly to gram-positive bacteria. The surgical excision of eschar and wound covering improved the outcome of the patients while prophylactic antibiotic treatment had no role in the incidence and outcome of the burn patients.

Copyright $\odot 2004$ S. Karger AG, Basel

\section{Introduction}

The burn is a devastating injury, jeopardizing the victim's life mainly at two junctures, firstly the hypovolaemia in acute stage, and secondly burn wound complications. Presently the hypovolaemia-related complications 
are effectively dealt with due to better understanding of burn pathophysiology, and therefore the outcome during the acute phase has improved. The burn wound and its sequelae still remain a challenge for the treating burn team. Extensive tissue devitalization due to burn injury and the moist environment due to outflow of serous exudate favour colonization and proliferation of varieties of organisms [1]. The dysfunction of the immune system due to burn [2-4], a large cutaneous bacterial load, the possibility of gastrointestinal bacterial translocation $[5,6]$, prolonged hospitalization and invasive diagnostic and therapeutic procedures, all contribute to wound sepsis and septicaemia. A burn patient is prone to have septicaemia as compared to other forms of trauma, because of the abovementioned factors [6-13]. The management of burn septicaemia remains a challenging task once it occurs, in spite of various infection control measures, advanced techniques for early detection of microorganisms, and the availability of various broad-spectrum antibiotics [8-13]. The outcome of a burn patient depends on the severity of the wound, resuscitation measures, wound coverage, wound sepsis and finally the management of septicaemia when it occurs $[1,7,9,10]$.

This study was undertaken to analyse the demographic and clinical factors associated with burn septicaemia patients in Kuwait.

\section{Subjects and Methods}

Two thousand and eighty-two cases were treated as in-patients at the Burns Unit, Al-Babtain Centre for Burns and Plastic Surgery, Kuwait, during the 9-year period from June 1992 to May 2001. The Centre is the only health facility that caters to burns in Kuwait and comprises 44 beds including 8 beds in the Intensive Care Burn Unit. Kuwaitis constitute about $38 \%$ of the total population, which was about 2.2 million in the year 2001. A total of 166 patients, who had septicaemia either on single or multiple occasions during their stay in the hospital, were studied.

Total body surface area (TBSA) burn percentage was estimated according to the Lund-Browder chart, and the fluid resuscitation was carried out according to the Parkland formula. The clinical diagnosis of the inhalation injury was confirmed by bronchoscopy and the patients were intubated and ventilated till recovery or otherwise. The nutritional requirement in burn catabolic state was calculated as 2$3 \mathrm{~g}$ of protein and 50-60 kcal for each percentage of burn surface from $48 \mathrm{~h}$ onward post burn. A mixture containing $1 \mathrm{kcal} / \mathrm{ml}$ was given orally to all patients from the 3rd post-burn day and 77 (46\%) of the patients were supplemented with parenteral nutrition.

Penicillin was used as prophylaxis in burn patients requiring resuscitation till December 1992. From January 1993 to December 1996 amikacin and piperacillin were used as prophylaxis in $\geq 40 \%$ burns in adults and $\geq 25 \%$ in children. From January 1997 onward no antibiotic prophylaxis was administered to the patients. The use
Table 1. Demographic characteristics of septicaemic patients

\begin{tabular}{llll}
\hline $\begin{array}{l}\text { Demographic } \\
\text { characteristics }\end{array}$ & Number & Age, years & p value \\
\hline All patients & 166 & $\begin{array}{l}26.5 \pm 1.43 \\
(45 \text { days-70 years })\end{array}$ & - \\
Sex & & $25.6 \pm 1.84$ & NS \\
$\quad$ Male & 99 & $27.8 \pm 2.28$ & \\
$\quad \begin{array}{l}\text { Female } \\
\text { Nationality }\end{array}$ & 67 & $20.9 \pm 3.05$ & 0.001 \\
$\quad$ Kuwaiti & 54 & $29.2 \pm 1.48$ & \\
$\quad$ Non-Kuwaiti & 112 & & \\
\hline
\end{tabular}

of antibiotics in burn wound sepsis and septicaemia was strictly governed by antibiotic policy which was started in 1992 and revised every 6 months. The microbiological surveillance protocol applicable to all burn patients included swabs from wound(s), nose, throat, and perineum on admission and subsequent wound swabs from burn wound twice a week.

The burn wounds were dressed with Sofratulle in superficial burns and Flamazine (1\% silver sulphadiazine) in deep burns. Early excision of $15-20 \%$ burn area in one operation and skin grafting with either autografts or auto- and homografts were carried out for thirddegree burns and the deep dermal burns of functional areas.

The diagnosis of septicaemia was based on the signs of disorientation, hyperpyrexia or hypothermia, circulatory embarrassment, petechial haemorrhages, unhealthy burn wound, early eschar separation, increasing oedema in unburned area, thrombocytopenia and leucocytosis. In clinically diagnosed patients two sets of blood samples at an interval of $1 \mathrm{~h}$ were taken from different sites for culture. The patients were treated with empirical antibiotic therapy till the blood culture report was available and the antibiotics were changed if needed.

The data were recorded for age, sex, nationality, cause and percentage of burn, response to resuscitation, inhalation injury, intubation, septicaemia on post-burn day, number of septicaemic episodes, the organisms responsible in each episode, therapy, and finally the patient's outcome for analysis.

SPSS (PC version 11.0) software was used for the data management and statistical analysis. The mean values were compared using $t$ test and ANOVA with post hoc Bonferroni test for multiple comparisons. Chi square was applied for any association and trend. A probability level of $\mathrm{p}<0.05$ was considered significant.

\section{Results}

One hundred and sixty-six (8\%) burn patients, who had septicaemia amongst 2,082 cases treated, comprised 99 (59.6\%) males and 67 (40.4\%) females (M:F ratio 3:2) with a mean age of $26 \pm 1.43$ years (table 1). Kuwaitis and non-Kuwaitis were 54 and 112, respectively. The mean age of Kuwaitis was significantly lower than of nonKuwaitis $(\mathrm{p}<0.001)$. The age and sex distribution showed 
Fig. 1. Septicaemic patients according to age group and gender.

Table 2. Septicaemic patients according to TBSA burn percentage and cause of burn

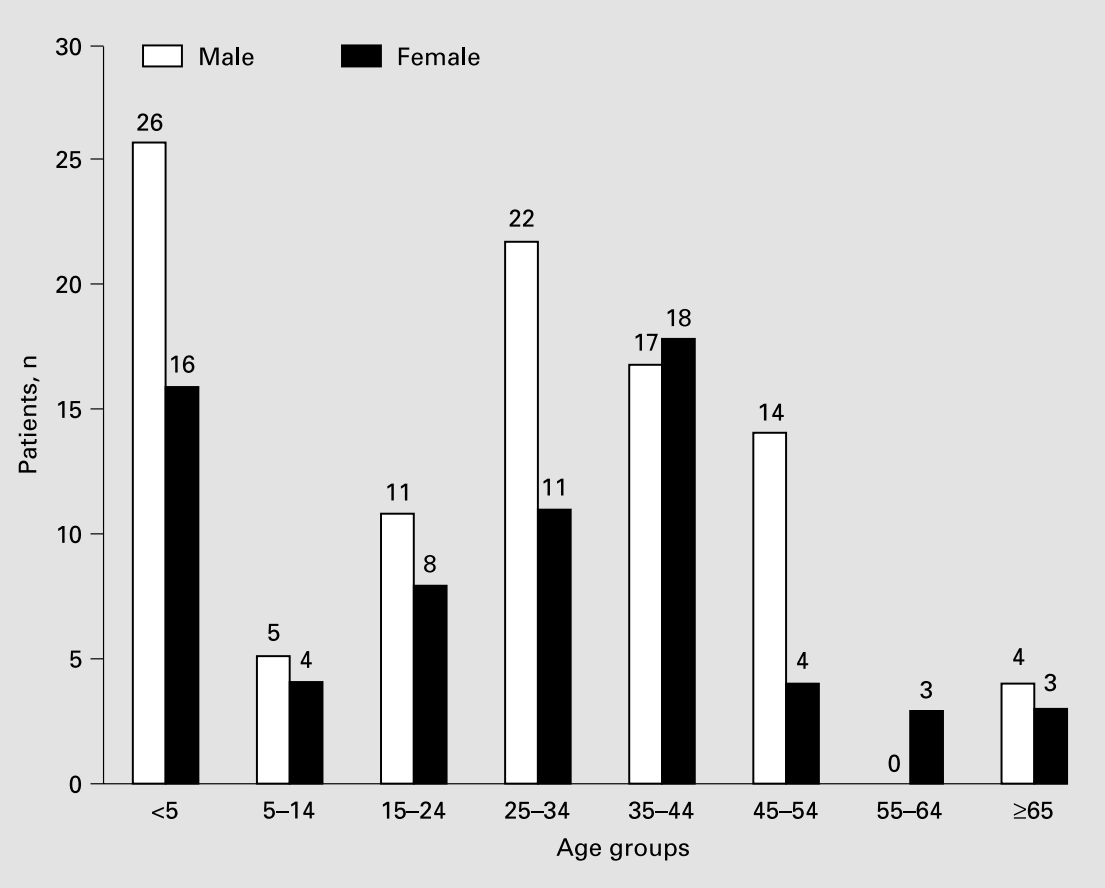

\begin{tabular}{lcclll}
\hline $\begin{array}{l}\text { TBSA } \\
\text { percentage } \\
\text { of burn }\end{array}$ & \multicolumn{2}{l}{ Cause of burn } & $\begin{array}{l}\text { Total } \\
(\mathrm{n}=166)\end{array}$ \\
\cline { 2 - 5 } $\begin{array}{l}\text { scald } \\
(\mathrm{n}=32)\end{array}$ & $\begin{array}{l}\text { flame } \\
(\mathrm{n}=128)\end{array}$ & $\begin{array}{l}\text { electric } \\
(\mathrm{n}=3)\end{array}$ & $\begin{array}{l}\text { others } \\
(\mathrm{n}=3)\end{array}$ & \\
\hline$\leq 10$ & 7 & 5 & 2 & 1 & 15 \\
$11-20$ & 13 & 13 & - & 1 & 27 \\
$21-30$ & 8 & 21 & - & - & 29 \\
$31-50$ & 3 & 32 & 1 & 1 & 37 \\
$51-70$ & 1 & 31 & - & - & 32 \\
$71-90$ & - & 24 & - & - & 24 \\
$>90$ & - & 2 & - & - & 2 \\
Mean (\% burn) & 20.2 & 48.7 & 14.7 & 17.3 & 42.0 \\
Range & $3-60$ & $6-95$ & $2-40$ & $2-38$ & $2-95$ \\
\hline
\end{tabular}

Flame vs. scald ( $\mathrm{p}<0.001)$, flame: $<20$ vs. $>20(\mathrm{p}<0.001)$. male predominance almost in all the age groups (fig. 1). The children up to 5 years of age comprised $25.3 \%$ and the age group $25-44$ years were $41 \%$ of all the cases, significantly higher $(\mathrm{p}<0.001)$ cases were recorded among Kuwaiti children $(<14$ years) and non-Kuwaitis $(25-44$ years). The mean TBSA burn was $42 \%$ ranging from 2 to $95 \%$ (table 2). The flame was the predominant cause of burn $(77.1 \%)$. The percentage of burn was significantly higher in flame than scald burn $(\mathrm{p}<0.001)$. However, the mean age among scald cases was 6.2 years, which was significantly lower $(\mathrm{p}<0.0001)$ than other causes.

The Parkland formula was used to satisfactorily resuscitate $142(85.5 \%)$ of the patients, while the remaining 24 $(14.5 \%)$ had difficult resuscitation either due to the severity of the burn, inhalation injury or both. Thirty-nine $(23.5 \%)$ patients had inhalation injury along with cutaneous burns, therefore, they were intubated on admission. 
Table 3. Post-burn day (PBD) according to the number of septicaemic episodes

\begin{tabular}{lcllll}
\hline PBD & \multicolumn{2}{l}{ Episodes } & & \multirow{2}{*}{ Total } \\
\cline { 2 - 4 } & one & two $^{1}$ & three $^{1}$ & $\geq$ four $^{1}$ & \\
\hline $0-3$ & 14 & 1 & - & 1 & 16 \\
$4-5$ & 15 & 1 & - & 1 & 17 \\
$6-10$ & 39 & 5 & 1 & 4 & 49 \\
$11-15$ & 28 & 6 & 2 & - & 36 \\
$16-20$ & 10 & 2 & 2 & 3 & 17 \\
$21-25$ & 5 & - & 2 & 1 & 8 \\
$26-30$ & - & 3 & 1 & - & 4 \\
$31-35$ & 2 & 2 & - & - & 4 \\
$>35$ & 10 & 4 & - & 1 & 15 \\
Total (\%) & $123(74.1)$ & $24(14.5)$ & $8(4.8)$ & $11(6.6)$ & 166 \\
Mean PBD & 12.8 & 17.9 & 9.0 & 5.6 & 13.5 \\
Range & $1-105$ & $1-65$ & $5-30$ & $3-19$ & $1-105$ \\
\hline
\end{tabular}

$\operatorname{PBD}(\leq 20$ and $>20)$ vs. number of episodes $(\geq 1)$ : $p<0.011$. 1 PBD of first episode only in these patients.

Table 4. Causative microorganisms for the septicaemia

\begin{tabular}{lrr}
\hline Organisms isolated & \multicolumn{2}{c}{ Episodes $(\mathrm{n}=253)$} \\
\cline { 2 - 3 } & $\mathrm{n}$ & $\%$ \\
\hline MRSA & 108 & 42.7 \\
Acinetobacter & 33 & 13.0 \\
MRSE & 25 & 9.9 \\
Pseudomonas & 22 & 8.7 \\
Staphylococcus aureus & 11 & 4.3 \\
Enterococci & 11 & 4.3 \\
Escherichia coli & 3 & 1.2 \\
Klebsiella & 4 & 1.6 \\
Serratia & 1 & 0.4 \\
Proteus & 1 & 0.4 \\
Candida & 2 & 0.8 \\
Mixed & 32 & 12.7 \\
\hline
\end{tabular}

The 166 patients had either single or multiple (2-10) episodes of septicaemia amounting to a total of 253, in 16 patients the first episode occurred as early as $72 \mathrm{~h}$ post burn but the maximum number of episodes occurred between 6 and 15 days post burn. The number of postburn days was significantly higher $(\mathrm{p}<0.011)$ among cases with more than one episode, as compared to those with one episode only (table 3). One hundred and fiftyfive $(61.3 \%)$ episodes were due to gram-positive organ-
Table 5. Septicaemic patients who underwent surgery and their outcome

\begin{tabular}{lclc}
\hline $\begin{array}{l}\text { Skin grafting } \\
\text { sessions }\end{array}$ & Patients & $\begin{array}{l}\text { \% burn } \\
\text { mean (range) }\end{array}$ & $\begin{array}{l}\text { Outcome } \\
\text { (\% survival) }\end{array}$ \\
\hline No surgery & 42 & $47.4(3-95)$ & 54.8 \\
$\quad 1$ session & 43 & $29.6(2-93)$ & 76.7 \\
2 sessions & 34 & $34.9(2-85)$ & 85.3 \\
3 sessions & 22 & $45.2(2-85)$ & 86.4 \\
4 sessions & 4 & $45.3(23-60)$ & 100 \\
$>5$ sessions (5-12) & 21 & $63.8(35-90)$ & 90.5 \\
Total & 166 & $42.0(2-95)$ & 76.5 \\
\hline
\end{tabular}

Outcome vs. surgery $(\mathrm{p}<0.003), \mathrm{OR}=4.3(95 \%$ CI: $1.98-9.31)$.

isms, mainly methicillin-resistant Staphylococcus aureus (MRSA), 2 due to Candida and 32 (12.7\%) were polymicrobial (table 4). Similar organisms as in the blood were also isolated from the burn wounds in most of the cases.

One hundred and twenty-four patients $(74.1 \%)$ had 345 sessions of skin grafting operation (range 1-12 sessions) and the survival rate was significantly higher ( $\mathrm{p}<$ 0.003 ) than in non-surgically treated patients (table 5). Of the 124 surgically treated patients, 113 (91.9\%) survived while only $23(55 \%)$ of the 42 non-surgically treated patients survived. Of the 21 patients, who had 5-12 surgeries each (total of 140 sessions), 19 survived.

Thirty-nine (23.5\%) patients, 14 males and 25 females with a mean age of 31 years, died following septicaemic episodes. Thirty-eight patients sustained flame burn mainly due to cooking gas accident or clothes on fire, and 1 had chemical (ammonia) burn due to leakage of ammonia in petrochemical industries during repair. Twenty-six $(67 \%)$ of the 39 patients with inhalation injury died following septicaemic episodes. The mortality in relation to post-burn days varied from 3 to 108 days with a mean of 27 days, and 15 patients $(9.1 \%)$ died within the first 10 days following burn injury. Multiple organ failure was the main cause of death in $71.8 \%$ of the septicaemic patients.

\section{Discussion}

The outcome of a burn patient depends on the burn severity, resuscitation measures, wound coverage, wound sepsis and finally the management of septicaemia, when it occurs. The high incidence of septicaemia amongst age 
groups up to 5 and 21-50 years showed their vulnerability. The high incidence amongst males and non-Kuwaitis as noted in the study can be explained on the basis of similar patterns of burn injuries. The high incidence of septicaemia among non-Kuwaitis could be due to their exposure and involvement in occupational and domestic activities. Flame burn patients were susceptible to develop septicaemia because of their extensive burn surface, deep wounds, and associated inhalation injury as observed in the study. Though, septicaemia can occur even in smaller percentages of burn, most $(75 \%)$ of them had more than $20 \%$ TBSA burned. The combination of extensive burn and inhalation injury were two important risk factors for the occurrence of septicaemia as observed in the study.

Resuscitation by the Parkland formula [14] was found to be satisfactory in the majority of our patients $(85.5 \%)$, but the presence of an inhalation injury [15] resulted in difficult resuscitation. The intravascular lines and endotracheal tubes, though known as risk factors, could not be incriminated as the source because the intravascular sites indicated no thrombophlebitis and most of the intravascular cannulae and endotracheal tubes were negative on culture. Silver sulphadiazine (1\% Flamazine) as topical agent [16] and institution of early nutrition during hypercatabolic state [17] were found to be satisfactory managements and might have helped the better outcome in these patients.

The penicillin prophylaxis was discontinued because beta-haemolytic Streptococcus cellulitis was rare in our patients [18] and, as demonstrated by other studies, it is of no benefit and may even be harmful [19, 20]. Piperacillin and amikacin prophylaxis, used during 1993-1996, was stopped in January 1997 on the grounds that specific antibiotics should be given if sepsis or septicaemia was proved clinically or microbiologically. As there was neither increase in the incidence of septicaemia nor mortality amongst septicaemic patients following stoppage of prophylactic antibiotics, we suggest that the use of prophylactic antibiotics has no role in the incidence and outcome of our burn patients.

It is generally considered that occurrence of septicaemia during the 1st week post burn is rare, but a number of our patients had septicaemia during the 1st week (table 3), and this is a significant clinical observation in terms of management of burn patients. However, the majority of septicaemic episodes occurred during the 2 nd week post burn, as similarly observed by Wurtz et al. [7]. The continuous clinical observation and timely culture of blood specimens helped in the early detection of septicaemia. Microbiological surveillance was helpful in starting the empirical antibiotic therapy in clinically diagnosed septicaemia confirming that the wound was the source for the spread of infection to the blood stream, because most of the septicaemic patients' blood isolates were similar to those that colonized/infected the burn wound surface.

The maximum number of septicaemic episodes by MRSA (table 4) might have been due to the fact that burn units are a major source of MRSA, and it has been found that our burn unit also is endemic for this organism [2123]. The long hospital stay and exposure to numerous antibiotics might have favoured MRSA nosocomial infection in these patients. Numerous methicillin-resistant Staphylococcus epidermidis (MRSE) septicaemic episodes suggest that this organism should be considered as a potential pathogen for burn septicaemia, and should not be ignored as a skin contaminant.

Enterococcus has not been reported as a frequent cause of septicaemia in the past but recent studies indicate an increasing incidence of enterococcal bacteraemia in burn patients, and the presence of $4.3 \%$ septicaemia due to Enterococcus in this study supports the observations made by other investigators [24, 25]. The incidence of gram-negative bacilli, particularly the Pseudomonas septicaemic episodes, was much lower than in other studies $[13,26]$, and the reasons for this decline may be due to the increasing frequency of gram-positive cocci as nosocomial pathogens, and frequent use of antibiotics effective against Pseudomonas [27]. Acinetobacter, another important gram-negative organism, showed increased septicaemic frequency compared to Pseudomonas as a lone pathogen as well as in polymicrobial septicaemia. The various factors, such as burn surface of more than $50 \%$ TBSA, prolonged hospital stay ( $>2$ weeks), use of multiple broad-spectrum antibiotics, and delay in wound closure, favour the colonization of burn wounds with the multiresistant nosocomial pathogens of the unit leading to polymicrobial sepsis. Fungal septicaemia is not uncommon in burn patients $[7,11]$ and two septicaemic episodes due to this in the study shows its emergence in this unit.

The mortality rate $(23.5 \%)$ in septicaemic patients was lower than in other studies [11, 28], and this may be attributed to adequate resuscitation, continuous clinical and microbiological surveillance and prompt blood culture, leading to quick detection of aetiology, institution of appropriate antibiotics, care for nutrition, early excision and wound coverage. 


\section{Conclusion}

The age groups up to 5 and 25-44 years (male nonKuwaitis) with extensive flame burns were prone to develop septicaemia. The Parkland formula was a satisfactory resuscitation method, but the presence of inhalation injury resulted in difficult resuscitation. Septicaemia occurred within 2 weeks but also as early as 3 days post burn. The burn wound was the likely source of the entry of organ- isms into the blood stream and gram-positive organisms such as MRSA were the common causative factor. The use of prophylactic antibiotics had no effect on the incidence and mortality in burn septicaemia. The low mortality rate might be attributed to adequate resuscitation, continuous clinical and microbiological surveillance and prompt blood culture leading to quick detection of aetiology, institution of appropriate antibiotics care for nutrition, early excision and wound coverage.

\section{References}

1 Williams WG, Phillips LG: Pathophysiology of the burn wound: in Herndon DN (ed): Total Burn Care. London, Saunders, 1996, pp 63 70

2 Ninneman JL: Immunological defenses against infection: Alterations following thermal injuries. J Burn Care Rehabil 1982;3:355-366.

3 Munster AM: Immunologic response of trauma and burns: An overview. Am J Med 1984;76: 142-145.

4 Winkelstein AU: What are the immunological alterations induced by burn injury? J Trauma 1984;24:S72-S83.

5 Deitch EA, Berg RD: Bacterial translocation from the gastro-intestinal tract: A mechanism of infection. J Burn Care Rehabil 1987;8:475482.

6 Jones WG 2nd, Minei JP, Barber AE, Rayburn JL, Fahey TJ 3rd, Shires GT 3rd, Shires GT: Bacterial translocation and intestinal atrophy after thermal injury and burn wound sepsis. Ann Surg 1990;211:399-405.

7 Wurtz R, Karajovic M, Dacumos E, Jovanovic $\mathrm{B}$, Hanumadass M: Nosocomial infections in a burn intensive care unit. Burns 1995;21:181184.

8 Magnusson MR, Pegg SP: Vibrio cholerae non01 primary septicaemia following a large thermal burn. Burns 1996;22:44-47.

9 Bang RL, Gang RK, Sanyal SC, Mokaddas E, Ebrahim MK: Burn septicaemia: An analysis of 79 patients. Burns 1998;24:354-361.

10 Dayoub A, Zeidan F, Hadidy S: Infection in burns: Experience of a teaching hospital in Syria. Ann Medit Burns Club 1995;8:17-19.
11 Donati L, Scamazzo F, Geriasoni M, Magliano A, Stankov B, Fraschini F: Infection and antibiotic therapy in 4,000 burned patients treated in Milan, Italy, between 1976 and 1988. Burns 1993; 19:345-348.

12 Mokaddas EMA, Mustafa AS, Sanyal SC: The prevalence, antibiotic and plasmid profiles of methicillin resistant Staphylococcus aureus (MRSA) in the burns unit of a Kuwaiti hospital. Kuwait Med J 1996;28:435-439.

13 Lesseva MI, Hadjiiski OG: Staphylococcal infections in the Sofia Burn Centre, Bulgaria. Burns 1996;22:279-282.

14 Baxter CR: Guidelines for fluid resuscitation. J Trauma 1981;21:667-668.

15 Smith DL, Cairns BA, Ramadan F, Dalston JS, Fakhry JS, Rutledge R, Meyer AA, Peterson HD: Effect of inhalation injury, burn size, and age on mortality: A study of 1,447 consecutive burn patients. J Trauma 1994;37:655-659.

16 Monafo WW, Freedman B: Topical therapy for burns. Surg Clin North Am 1987;67:133-145.

17 Lown D: Use and efficacy of nutrition protocol for patients with burns in intensive care. J Burn Care Rehabil 1991;13:371-376.

18 Bang RL, Gang RK, Sanyal SC, Mokaddas E, Lari AR: Beta-hemolytic Streptococcus infection in burns. Burns 1999;25:242-246.

19 Dacso CC, Luterman A, Curreri PW: Systemic antibiotic treatment in burned patients. Surg Clin North Am 1987;67:57-68.
20 McManus AT, McManus WF, Mason AD Jr, Pruitt BA Jr: Beta-hemolytic streptoccocal burn wound infection are too infrequent to justify penicillin prophylaxis. Plast Reconstr Surg 1994;93:650.

21 Boyce JM, White R, Causey WA, Lockwood WR: Burn units as a source of methicillin resistant Staphylococcus aureus infections. JAMA 1983;249:2803-2807.

22 Taylor GD, Kibsey P, Kirkland T, Burroughs E, Tredget E: Predominance of staphylococcal organisms in infections occurring in a burn intensive care unit. Burns 1992;18:332-335.

23 Phillips LG, Heggers JP, Robron MC: Burn and trauma units as sources of methicillin resistant Staphylococcus aureus. J Burn Care Rehabil 1992;13:293-297.

24 Graninger W, Ragette R: Nosocomial bacteremia due to Enterococcus fecalis without endocarditis. Clin Infect Dis 1992;15:49-57.

25 Jones WG, Barie PS, Yurt RW, Goodwin CW: Enterococcal burn sepsis: A highly lethal complication in severely burned patients. Arch Surg 1986;121:649-653.

26 McManus AT, Mason AD, McManus WF, Pruitt BA: Twenty-five-year review of Pseudomonas aeruginosa bacteremia in a burn center. Eur J Clin Microbiol 1985;4:219-223.

27 Pruitt BA, Lindberg RB, McManus WF, Mason AD: Current approach to prevention and treatment of Pseudomonas aeruginosa infections in burned patients. Rev Infect Dis 1983; 5:S889-S897.

28 Polk HC: Supportive therapy in burn care: Consensus summary on infection. J Trauma 1979;19:894-896. 